\title{
Biological and chemical analyses of a laboratory-scale biofilter for oxygenate bioremediation in simulated groundwater
}

\author{
J. Purswani - G. A. Silva-Castro • I. M. Guisado • \\ J. González-López · C. Pozo
}

Received: 11 July 2012/Revised: 29 April 2013/Accepted: 26 May 2013/Published online: 26 June 2013

(C) Islamic Azad University (IAU) 2013

\begin{abstract}
Microbial remediation of methyl tert-butyl ether-contaminated aquifers has been widely studied since their cost/efficiency ratios are lower than other remediating techniques. Based on previous studies, simultaneous assessment of two inocula (Acinetobacter calcoaceticus M10 and a co-culture between strain M10 and Rhodococcus ruber E10) was performed for methyl tert-butyl ether bioremediation in a designed pilot-scale biofilter. A noninoculated biofilter was included for comparison. Temporary bioremediation of methyl tert-butyl ether (up to $80 \%$ removal) from the biofilter inoculated with the consortium was observed within 44 days. In addition, the taxonomic profile (temporal temperature gradient gel electrophoresis from RNA extracts) from the latter biofilter contained more active strains than in the other two systems. The presence of strains M10 and E10 in temporal temperature gradient gel electrophoresis analysis from RNA extracts and high presence of strain E10 in temporal temperature gradient gel electrophoresis analysis of DNA extracts, along with alkB amplification of both strains in the biofilter, suggest that the co-culture inoculum was responsible for the methyl tertbutyl ether removal.
\end{abstract}

Electronic supplementary material The online version of this article (doi:10.1007/s13762-013-0348-3) contains supplementary material, which is available to authorized users.

J. Purswani - G. A. Silva-Castro - I. M. Guisado - C. Pozo Environmental Microbiology Group, Institute of Water Research, University of Granada, Granada, Spain

J. Purswani · J. González-López · C. Pozo $(\bowtie)$ Department of Microbiology, University of Granada, C/Ramón y Cajal no. 4, 18071 Granada, Spain e-mail: clpozo@ugr.es
Keywords Methyl tert-butyl ether - Rhodococcus ruber . Acinetobacter calcoaceticus . Temporal temperature gradient gel electrophoresis

\section{Introduction}

Groundwater is the main drinking and irrigating source of water in most countries around the world. In several southern European countries such as Spain, Portugal, and Italy, the existing groundwater abstraction is equal to or greater than the groundwater availability in the country. In addition, desertification is on the increase too (UNEP 2004); thus, accidental spills or unnoticed leakages of unleaded gasoline will quite often contaminate essential aquifers and endanger this natural resource. Fuel oxygenates, such as methyl tert-butyl ether (MTBE), ethyl tertbutyl ether (ETBE), and tert-amyl methyl ether (TAME), have been used to replace tetraethyl lead, consequently reducing harmful emissions in motorized vehicles; however, they are also the second most found contaminant detected in aquifers in the USA (de Lacy Costello et al. 2005). The European Environmental Agency's acknowledgment of the problems arising from fuel oxygenate contamination has been given less importance than the American counterparts, even though oxygenate spills have been detected throughout Europe (Germany, Austria, Belgium, Switzerland, Spain, Italy) in different environmental water bodies (Rosell et al. 2007). The presence of tert-butyl alcohol is also monitored, since this MTBE metabolite is more toxic than the initial contaminant (Schmidt et al. 2004).

Remediation technologies to palliate MTBE-contaminated groundwater include adsorption via activated carbon and other synthetic sorbents (Aivalioti et al. 2010), air 
sparging (Bass et al. 2000), membrane technology, phytoremediation, and biological technologies among others. Biological technologies have been tested with varying inoculants and at different operational conditions for MTBE removal, all with start-up times ranging from 10 to $>150$ days (Waul et al. 2007).

This paper describes the start-up and the effectiveness of using selected inocula against the possibility of natural attenuation in an aerated submerged biofilter during 2 months, assessing removal or transformation of gasoline oxygenates from a hypothetical recently contaminated site (spiked unfiltered groundwater samples). This paper also addresses the potential toxicity from the metabolic breakdown of these ethers, an issue often ignored by previous biotechnological papers. Furthermore, the paper studied the microbial diversity present in the system and the presence/ absence of two monooxygenases (ethB and alkB) depicted by Chauvaux et al. (2001) and Smith et al. (2003), respectively, using gene-specific primers described by Auffret et al. (2009). The research was performed at the Institute of Water Research, University of Granada, Spain, in 2011.

\section{Materials and methods}

\section{Chemicals}

All chemicals were of reagent grade or the highest purity available and were purchased from commercial sources. Methyl tert-butyl ether (99.9\% purity) was purchased from Fluka (Milwaukee, WI, USA), and TAME (97\% purity) was purchased from Sigma-Aldrich (Milwaukee, WI, USA).

\section{Groundwater samples}

Unchlorinated groundwater samples (25 L sample collected weekly) from a well located near a city (Los Vados, Granada, Spain. Geographical co-ordinates: $\left.+37^{\circ} 11^{\prime} 28.79^{\prime \prime},-3^{\circ} 40^{\prime} 35.61^{\prime \prime}\right)$ were transferred to the laboratory in sterile tanks. Groundwater samples were tested for the presence of oxygenates and BTEX (Benzene, toluene, ethylbenzene, and xylene); however, the groundwater was free of all of these compounds. Filtered $(0.22-\mu \mathrm{m}$ nitrocellulose filter, EZGSWG474-Millipore ${ }^{\circledR}$ ) and unfiltered groundwater were transferred to sterile glass bottles, amended with $150 \mathrm{mg} / \mathrm{L}$ of fuel ether, and used in continuous flow mode as influent in the biofilter. The glass bottles were not contained within a thermostat and were changed daily with freshly amended groundwater.
Bacterial strains

The bacterial strains used in this study, Acinetobacter calcoaceticus M10 (Colección Española de Cultivos Tipo-CECT 7739) and Rhodococcus ruber E10 (CECT 7740), were isolated from a hydrocarbon-contaminated soil site (Purswani et al. 2008) and preselected due to their ability to biotransform gasoline oxygenates, keep up their physiological activity, and to form a biofilm on an inert support material (i.e., Bioflow $9^{\circledR}$ ) in the presence of oxygenates MTBE and ETBE, respectively (Purswani et al. 2011a).

\section{Setup of biofilters}

The laboratory-scale biofilter used is described previously by Purswani et al. (2011a). Teflon (PFTE) tubing was used throughout the system, except at connections and at the pump region. Silicon and Marprene (Watson Marlow, Wilmington, MA, USA) tubing were tested, and the latter material was chosen since less oxygenate diffusion was observed [porosity of Marprene (gas permeability, $5.8 \mathrm{O}_{2}$ $\mathrm{cc} \mathrm{cm} \times 10^{-8} / \mathrm{cm}^{2} \mathrm{~s} \mathrm{~atm}$ ); porosity of silicone tubing (gas permeability, $400 \mathrm{O}_{2} \mathrm{cc} \mathrm{cm} \times 10^{-8} / \mathrm{cm}^{2} \mathrm{~s} \mathrm{~atm}$ )]. Oxygenate removal by air stripping in the biofilters was assessed under different hydraulic retention times and air flow rates for $100 \mathrm{mg} / \mathrm{L}$ MTBE, ETBE, and TAME. Air stripping was assessed by subtracting the effluent ether concentration from the influent ether concentration a day (12- and 24-h hydraulic retention time (HRT)) or two days before ( $48 \mathrm{~h}$ ).

Three biofilters were set up at the same time and were named D, E, and F. Biofilter D was selectively inoculated with bacterial strain A. calcoaceticus M10. The co-culture formed by A. calcoaceticus $\mathrm{M} 10$ and $R$. ruber E10 was used as selective inoculum in biofilter $\mathrm{E}$, and no strain was recirculated in biofilter $\mathrm{F}$.

The inoculated biofilters were incubated under controlled temperature $\left(20^{\circ} \mathrm{C}\right)$ for 8 weeks in continuous mode. The working conditions were the same for all the experiments: $5 \mathrm{~mL} / \mathrm{min}$ air, recirculating $(1.2 \mathrm{~L} /$ day $)$ pregrown inoculum in MY medium (Moraine and Rogovin 1966) during 5 days amended with $100 \mathrm{mg} / \mathrm{L}$ oxygenate. To ensure adaptation of the microorganisms to a minimal source, a further recirculation period was established, recirculating filtered groundwater amended with $0.1 \mathrm{~g} / \mathrm{L}$ glucose and $100 \mathrm{mg} / \mathrm{L}$ of MTBE for another 5 days. The control columns were not inoculated; however, uninoculated media were recirculated too.

After this initial period of biofilm formation on the support material, unfiltered groundwater amended with $150 \mathrm{mg} / \mathrm{L}$ of MTBE was pumped into the system at a flow rate of $800 \mathrm{~mL} /$ day, i.e., a HRT (hydraulic retention time) of $24 \mathrm{~h}$. 
Oxygenate analysis

The oxygenate concentrations of the groundwater samples were determined by GC/MS headspace technique. Periodically, $1.5 \mathrm{~mL}$ of the inoculated and control samples were placed (not filtered) into $2-\mathrm{mL}$ vials and clamped. The samples were heated at $90{ }^{\circ} \mathrm{C}$ during $90 \mathrm{~min}$, followed by the injection of $50 \mu \mathrm{L}$ of the gas phase into the GC/MS equipment (Hewlett-Packard 6890 GC coupled to a MS Hewlett-Packard 5973 mass selective detector, Palo Alto, CA, USA). The analysis was performed on a Quadrex capillary column (007-1, dimethylpolysiloxane-PHAT phase, $20 \mathrm{M} \times 0.18 \mathrm{~mm} \times 6.0 \mu \mathrm{m})$. The temperature program was $40^{\circ} \mathrm{C}(3.5 \mathrm{~min}), 10^{\circ} \mathrm{C} \min ^{-1}$ up to $85^{\circ} \mathrm{C}$, and $7{ }^{\circ} \mathrm{C} \min ^{-1}$ up to $235^{\circ} \mathrm{C}$. Helium was used as the carrier gas at a flow rate of $0.4 \mathrm{~mL} \mathrm{~min}^{-1}$. Quantification of MTBE and TAME was performed using an external standard calibration $(R>0.99)$. All samples were taken in triplicate, and the mean and standard deviations calculated.

\section{Biofilm sampling}

Bioflow $9^{\circledR}$ units with established biofilm were only taken at weeks 2 and 8 of each experimental period. Biofilm samples at 2 weeks belong to polyethylene units on the upper level of the biofilter, and biofilm samples at 8 weeks were taken from the polyethylene units of the whole system. Bioflow $9^{\circledR}$ units of each biofilter were resuspended in $1 \times$ PBS (phosphate-buffered saline solution) through vortexing and sonication during $30 \mathrm{~s}$. The biomass was harvested and treated according to the requirements of further procedures.

Observation of biofilm formation by field-emission scanning electron microscope (FESEM) technique

Bioflow $9^{\circledR}$ support samples were extracted after both recirculation periods, from the upper level of the biofilter. These were fixed and processed as described in Purswani et al. (2011a) and observed using a LEO 1530 field-emission scanning electron microscope (FESEM).

\section{DNA extraction}

Genomic DNA extraction from filter samples and biofilm samples was performed using the "FastDNA ${ }^{\circledR}$ SPIN Kit for Soil" and the FastPrep ${ }^{\circledR}$ Instrument (MP Biomedical, Santa Ana, CA, USA). Genomic DNA extraction from each cultivable strain was performed using the method described by Martín-Platero et al. (2007).

Weekly, 2 L of groundwater influent samples were filtered through $0.22-\mu \mathrm{m}$ nitrocellulose filter (EZGSWG474-Millipore). Each filter was stored in a sterile
15-mL falcon tube and processed as described previously (Purswani et al. 2011b).

Temperature gradient gel electrophoresis (TGGE) technique

Temperature gradient gel electrophoresis (TGGE) was performed according to Calderón et al. (2011) after amplification of $16 \mathrm{~S}$ rDNA with the primer set fD1 (5'-CCGA ATTCGTCGACAACAGAGTTTGATCCTGGCTCAG-3') and rD1 (5'-CCCGGGATCCAAGCTTAAGGAGGTGAT CCAGCC- $3^{\prime}$ ), and the anchored amplification of the V3 region in the $16 \mathrm{~S}$ rDNA with the primer set GC-P1 $\left(5^{\prime}-\mathrm{C}\right.$ GCCCGCCGCGCGCGGCGGGCGGGGCGGGGGCACG GGGGGCCTACGGGAGGCAGCAG-3') and P2 (5'-AT TACCGCGGCTGCTGG-3' ${ }^{\prime}$ ). Pattern differences and similarities were analyzed with GelComparII program using the Pearson's correlation coefficient. Microbial changes in the influent were calculated using the formula described in Marzorati et al. (2008), i.e., the percentage change was calculated by subtracting the percentage similarity from week to week from $100 \%$ ( $\%$ change $=100-\%$ similarity).

$e t h B$ and $a l k B$ PCR of biofilm samples

Polymerase chain reaction (PCR) amplification of known ether-degrading monooxygenases such as $e t h B$ and $a l k B$ was tested on the total genomic DNA extracted from biofilm samples developed on Bioflow $9{ }^{\circledR}$ grids at weeks 2 and 8 , as well as from bacterial strains isolated from the biofilm samples, and strains M10 and E10. The PCR conditions for the alkB gene were as follows: $96^{\circ} \mathrm{C}$ for $7 \mathrm{~min}$; a 30 cycle of $96{ }^{\circ} \mathrm{C}$ for $30 \mathrm{~s}, 40{ }^{\circ} \mathrm{C}$ for $40 \mathrm{~s}$, and $72{ }^{\circ} \mathrm{C}$ for $1 \mathrm{~min}$; and an extension of $10 \mathrm{~min}$ at $72{ }^{\circ} \mathrm{C}$. The PCR conditions for the $e t h B$ gene were as follows: $96{ }^{\circ} \mathrm{C}$ for $7 \mathrm{~min}$; a 30 cycle of $96{ }^{\circ} \mathrm{C}$ for $30 \mathrm{~s}, 40-60{ }^{\circ} \mathrm{C}$ gradient for $40 \mathrm{~s}$, and $72{ }^{\circ} \mathrm{C}$ for $1 \mathrm{~min}$; and an extension of $10 \mathrm{~min}$ at $72^{\circ} \mathrm{C}$. The primers for ethB amplification were: ethB-F2: $5^{\prime}$-CACGCGCTCGGC GACTGGCAGACGTTCAGT-3' and ethB-R2: 5'-TCCGA CGCACATGTGCGGGCCGTACCCGAA-3'. The primers for $a l k B$ were: alk-H1F-CIGIICACGAIITIGGICACAA GAAGG and alk-H3R-IGCITGITGATCIIIGTGICGCT GIAG (Auffret et al. 2009). These were first tested on the biofilm genomic DNA at weeks 2 and 8. Amplification of the $e t h B$ gene was negative under various conditions tested and thus were not tested on cultivable strains.

Toxicity analysis

Microtox $^{\circledR}$ system was used to measure acute toxicity on effluent samples from the biofilters at weeks $0,2,4,6$, and 8 . The bioluminescent Vibrio fischeri was grown against the 
effluent samples, where toxicity was expressed as the reduction of $50 \%$ luminescence from its initial luminescence $\left(\mathrm{EC}_{50}\right)$ (Onorati and Mecozzi 2004).

RNA extraction and retrotranscription of biofilter samples

Total RNA was extracted from biofilm samples using the FASTRNA ${ }^{\circledR}$ PRO KIT with the FastPrep ${ }^{\circledR}$ Instrument (MP Biomedical, Santa Ana, CA, USA), followed by a DNase digest. Samples were purified with Qiagen RNAeasy Total RNA purification kit, followed by reverse transcription using the Superscript II (Invitrogen) as described in the manual. The cDNA was used to amplify the $16 \mathrm{~S}$ rDNA, followed by the $\mathrm{V} 3$ region (with the primers described above).

\section{Results and discussion}

Microbial bioremediation of fuel ethers has been described previously (Waul et al. 2007); however, the approach offered in this study is to evaluate the chemical and biological aspects implied in the bioremediation of ethercontaminated groundwater by selective inoculation compared to non-inoculation, as well as the possible toxic effects that may occur during the process. Assuming that the microbial population has not been preselected by the presence of fuel ethers (since the groundwater tested negative for the presence of these), assessment of the use of the described biofilters for a recent ether-contaminated groundwater site was performed.

Air stripping of all three ethers in the designed biofilter was determined in order to assess how much of the removed fuel ether would be due to different air flow rates and hydraulic retention time (HRT). As can be observed from Fig. 1, increasing air flow rate and increasing hydraulic retention times (HRT), resulted in higher air stripping values. Although a $12 \mathrm{~h} \mathrm{HRT} \mathrm{and} \mathrm{an} \mathrm{air} \mathrm{flow} \mathrm{rate}$ of $0 \mathrm{ml} / \mathrm{min}$ resulted in the least MTBE stripped, these parameters would not be adequate for microbial ether degradation, since growth rates on MTBE are very low and MTBE biodegradation is best under aerobic conditions. Thus, a HRT of $24 \mathrm{~h}$ and $5 \mathrm{ml} / \mathrm{min}$ air flow rate was chosen for all assays performed, taking into account that approximately $40 \%$ MTBE would be air stripped.

In prior work, MTBE-degrading microorganisms Rhodococcus ruber E10 and Acinetobacter calcoaceticus M10 isolated from a hydrocarbon-contaminated soil site (Purswani et al. 2008) were grown individually and in coculture in liquid media to test for oxygenate removal and in the biofilter to test for biofilm formation as well as their spatial distribution (Purswani et al. 2011a). The main results concluded that strain E10 was found to be physiologically very active in the presence of MTBE and the exclusive use of this strain may be sufficient for MTBE bioremediation. However, its inability to attach to the Bioflow $9^{\circledR}$ units required the use of a co-culture inoculum for the biofilter designed in this study.

As a consequence, three biofilters were set up simultaneously and were named D, E, and F. The biofilter named $\mathrm{D}$ was selectively inoculated with bacterial strain A. calcoaceticus M10 via a 5-day recirculation period. The bacterial co-culture formed by A. calcoaceticus M10 and $R$. ruber E10 was also used as a selective inoculum in biofilter E, and no strain was recirculated in biofilter $\mathrm{F}$ (a control biofilter) with the intention of assessing the degrading capacity of the autochthonous groundwater microbiota. To confirm biofilm formation on Bioflow $9^{\circledR}$ grids before the entry of unfiltered groundwater amended with MTBE, SEM micrographs (Online Resource 1 Fig. 1) were obtained after both recirculation periods.

MTBE concentrations, external temperature, and toxicity units were monitored throughout the 8 -week period in the biofilters, and as can be observed from Fig. 2a, there is approximately $60 \mathrm{mg} / \mathrm{L}$ decrease from the influent to the effluent from the start, which coincides with the amount lost by air stripping at $24 \mathrm{~h}$ HRT and $5 \mathrm{ml} / \mathrm{min}$ air flow rate as observed in Fig. 1; thus, this decrease is not accountable by microbial degradation. The external temperature (Fig. 2b) during the 8-week period decreased slightly throughout and may have caused a general increase in effluent MTBE concentrations of all the biofilters, since a reduction in temperature will have a decreasing effect on the amount of MTBE air stripped from the influent tank, which was not kept in a thermostat. Biofilter E clearly has a negative MTBE concentration tendency, and averaged data points shown for this seem to decrease as from week 3 , to the lowest data point on week 6 ( $80 \%$ decrease accountable by microbial degradation). The toxicity levels observed in all the effluents (Fig. 2c) decreased in unison; nevertheless, it was lowest for biofilter E during the same period where the lowest MTBE concentration is observed. The metabolite TBA was monitored; yet, no detectable levels were observed throughout the sampling period.

The biofilm changes caused by the influent microbiota were analyzed by observing the similarities between the microbiota present in biofilms formed at weeks 2 and 8 , with those of the weekly influent microbiota (Fig. 3a) from TGGE tests using GelComparII. The biofilm communities present in biofilters $\mathrm{D}, \mathrm{E}$, and $\mathrm{F}$ at week 2 are clustered with the communities present in the influent during weeks 1,2 , and 3 (clustered at $\sim 45 \%$ similarity). The same pattern was observed with biofilter profiles in week 8 ; yet, these were more similar (clustered at $\sim 65 \%$ similarity) than those in week 2 . Overall, the microbial changes within the 
Fig. 1 Air stripping of ether compounds at different hydraulic retention times and flow rates of infused air. Air pressure was constant at $5 \mathrm{Kpa}$

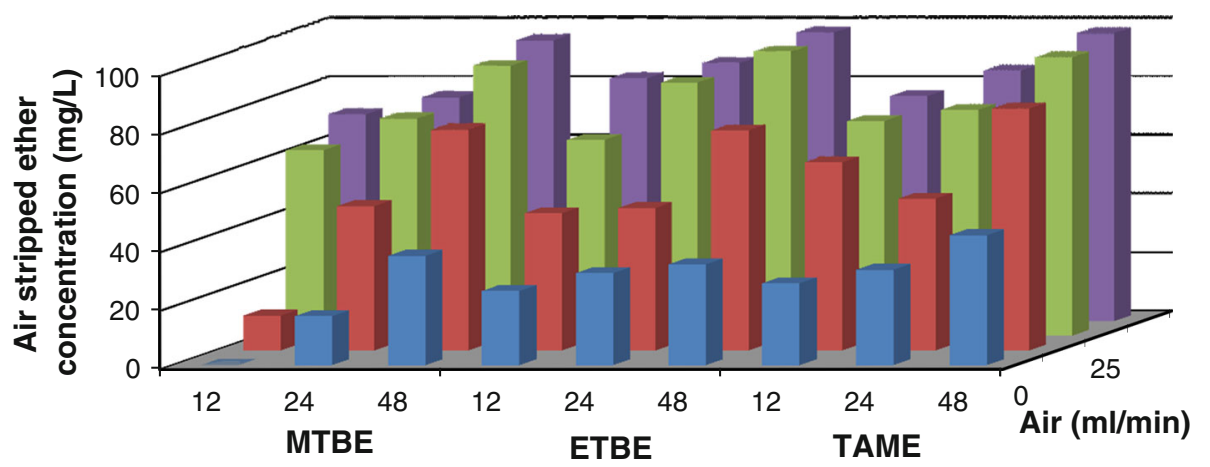

Hydraulic retention time (Hours)
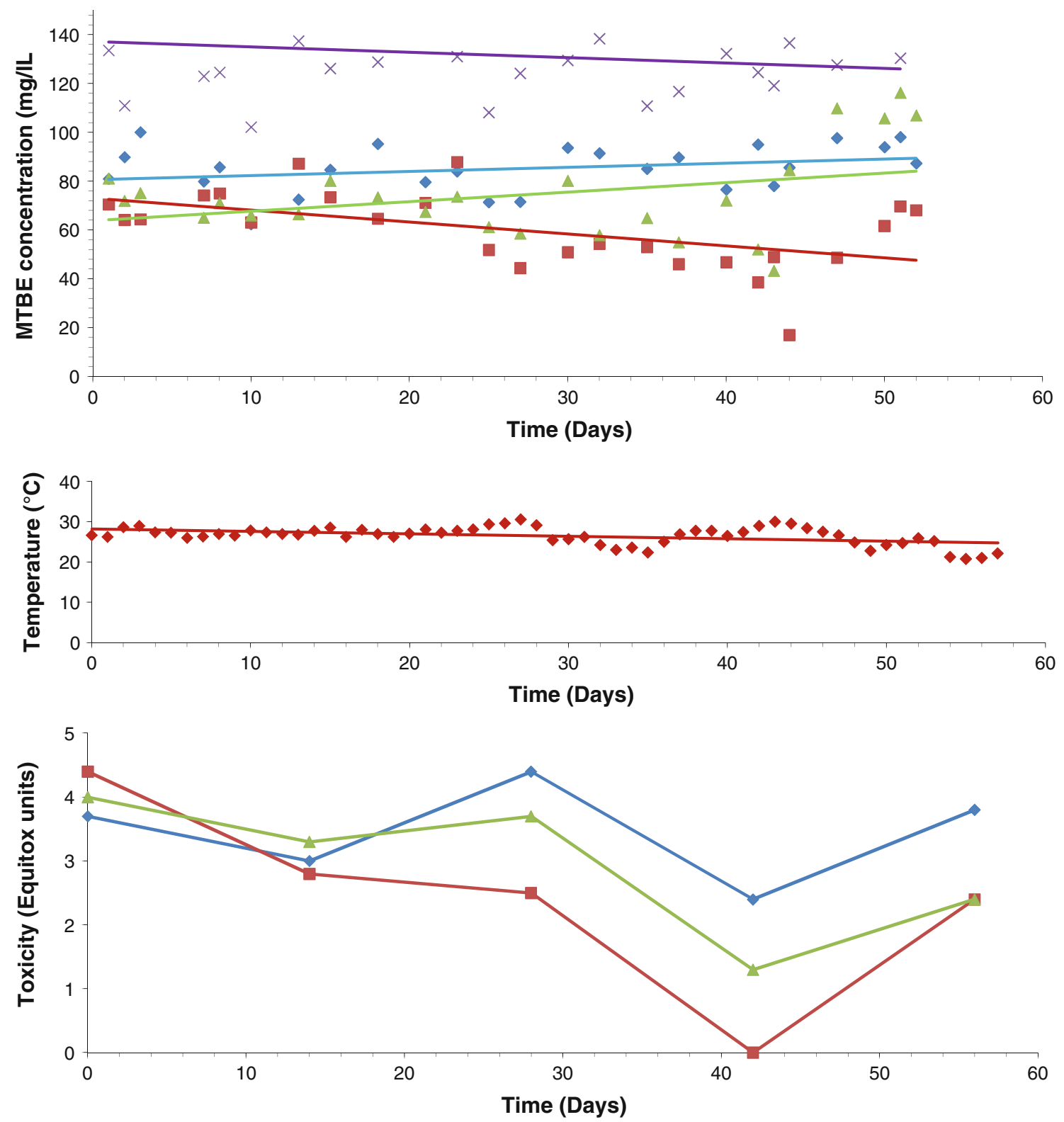

Fig. 2 a MTBE influent and effluent concentrations from biofilters. b External temperature during the experiment period. c Microtox evaluation of the effluent of columns $D, E$, and $F$. Multiple symbol- influent, filled diamond-Acinetobacter calcoaceticus M10 inoculated biofilter. Filled triangle - consortia M10-E10 inoculated biofilter, filled square — uninoculated biofilter 
biofilm were directly influenced by the incoming groundwater microbiota from the previous 2 weeks.

Weekly dynamic changes in the influent microbiota were also plotted in a moving window analysis as shown in Fig. 3b. The first data point at time 0 had to be $100 \%$ since there was a change in the influent from sterile medium to the biodiversity found in the first incoming groundwater supply. Observation during the first 4 weeks shows that weekly change is $\sim 50 \%$, followed by 3 weeks of $\sim 20 \%$ weekly microbial change. According to Marzorati et al. (2008), if the rate of change $(\Delta t)$, calculated as the average of the moving window curve data points, is higher than $25 \%$, "a lot of species come to dominance and leave the bacterial community resulting in broad dynamics, probably causing loss of overall coherence." The average $\Delta \mathrm{t}$ of the influent microbiota overall is very high; coincidently, its lowest $\Delta \mathrm{t}$ period can be observed between week 6 and 8 .

On the whole, changes in MTBE concentration and toxicity, within the three biofilters (Fig. 2), can only be explained by an external factor: the presence of groundwater MTBE-degrading strains, which were being established in all biofilters. Nevertheless, strain E10 seems to play the largest role in MTBE degradation, since in the other two biofilters, there was no significant MTBE concentration decrease. Additionally, "stabilization" of the microbial community in the influent helped maintain the degrading microbial population by reducing competition, since the biofilm biodiversity was highly linked to the incoming microbiota, and the highest MTBE concentration reduction was observed with a reduction in influent biodiversity between week 5 and 6 (Fig. 4). Unfortunately, the possible loss of specific autochthonous microorganisms after week 6 also meant the loss of MTBE removal.

In previous results (Purswani et al. 2011a), MTBE removal from the co-culture assayed in agitating flasks was not observed; however, both strains in the biofilm were exerting mutual avoidance, (strain E10 was observed at the periphery of the strain M10 agglomerate). In this study, both these strains have proved to exert mutual cooperation in biodegrading MTBE; however, it was puzzling as to why they were not cooperating in liquid media. A previous study (Harcombe 2010) concluded that growth in a spatially structured environment (such as in biofilms) assured that the benefits of cooperation were preferentially received
Fig. 3 a Cluster analysis of the biofilter columns treating MTBE, using the Pearson correlation (position tolerance-0.26). $D$ inoculated biofilter with strain M10, E-inoculated biofilter with strains M10 and E10, and $F$-uninoculated biofilter. b Microbial dynamics of the influent of biofilters treating MTBE during the experimental period as described in Marzorati et al. (2008)

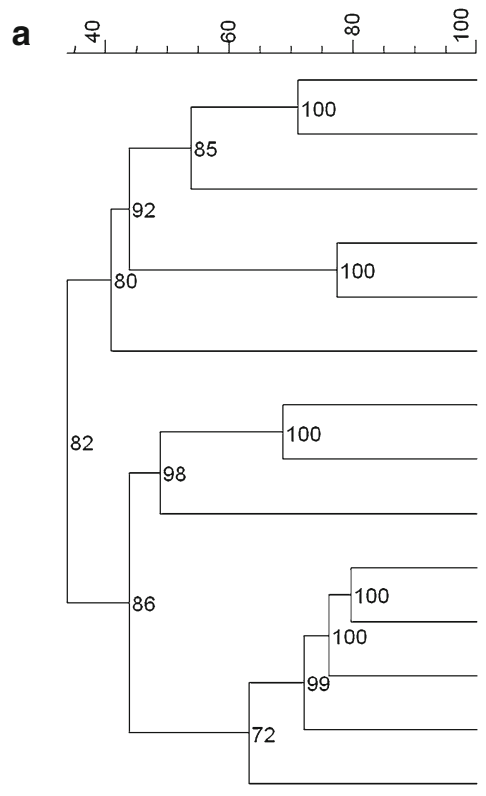

Biofilter D week 2

Biofilter F week 2

Influent week 3

Influent week 1

Influent week 2

Biofilter $\mathrm{E}$ week 2

Influent week 4

Influent week 6

Influent week 5

Influent week 7

Biofilter E week 8

Biofilter F week 8

Influent week 8

Biofilter D week 8

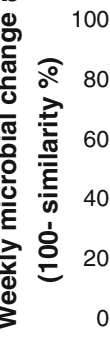

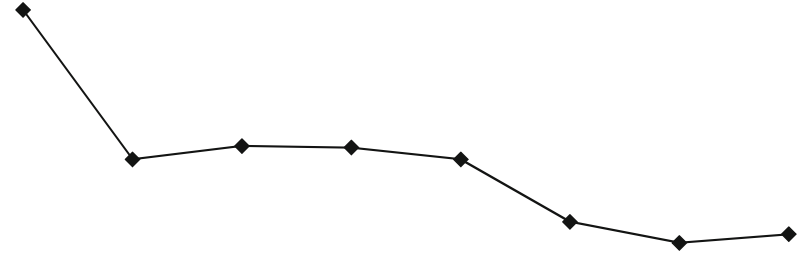

10

20

30

Time (days) 

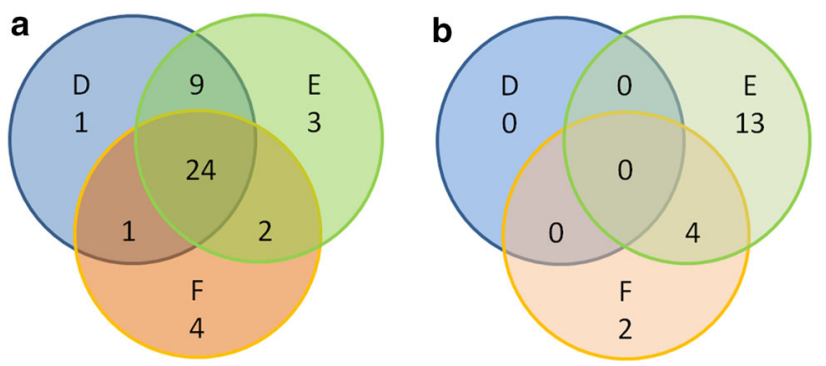

Fig. 4 Venn diagram showing the number of V3 bands exclusive or shared among the other biofilters at the end of the 56-day period with MTBE from a whole genomic DNA extracted samples and $\mathbf{b}$ whole genomic RNA extracted samples. $D$-inoculated biofilter with strain M10, E-inoculated biofilter with strains M10 and E10, and Funinoculated biofilter

by cooperative genotypes, whereas novel cooperation disappeared if the spatial structure was removed. This has also been proved using the rock-paper-scissors analogy in digital microorganisms (Kerr et al. 2002). Thus, adaptation of these strains in the hydrocarbon-contaminated soil site probably exerted mutual cooperation exclusively in localized spaces.

The TGGE analytical data obtained from DNA and RNA profiles of the biological community (Online
Resource 1 Fig. 2a and Online Resource 1 Fig. 3) were processed further resulting in band isolate sequences aligned and drawn in phylogenetic trees (Fig. 6b and Online Resource 1 Fig. 2b).

The TGGE analysis performed on DNA and RNA biofilm extracts at week 8 was processed using the statistical package Venn Diagrams for R (Chen and Boutros 2011) (Fig. 5), showing the band similarities and differences among the three biofilters. Clearly indicated via number of RNA bands, the microbial community present in biofilter $\mathrm{E}$ was more active compared to those in biofilters $\mathrm{D}$ and $\mathrm{F}$. The percentage of active strains versus total number of strains (as accounted by the TGGE profiles) was 0,46 , and $18 \%$ in the biofilters $\mathrm{D}, \mathrm{E}$, and $\mathrm{F}$, respectively.

Relative band intensities from DNA TGGE profiles, along with their corresponding taxonomic assignations, were used to compile qualitative pie charts to observe changes in taxa present in the biofilters at weeks 2 and 8 (Fig. 5). Little community changes from the taxonomically identified bands occurred from weeks 2 to 8 in biofilter D. The same could be said for changes in biofilter E, with the exception of a diminished presence of Psedumonaceae at week 8. As for the changes which occurred in biofilter $F$ from week 2 to 8 , we note that there is a reduction in
Fig. 5 Relative DNA

quantitative band intensity from TGGE analysis, at weeks 2 and 8. NS/NA-not sequenced/not amplified. Mixed population in a single band (MPB).

Unclassifiable-sequenced, unlike other species $(92 \%$ or lower similarity). Alphasequences identified closely related to Alphaprotebacteria
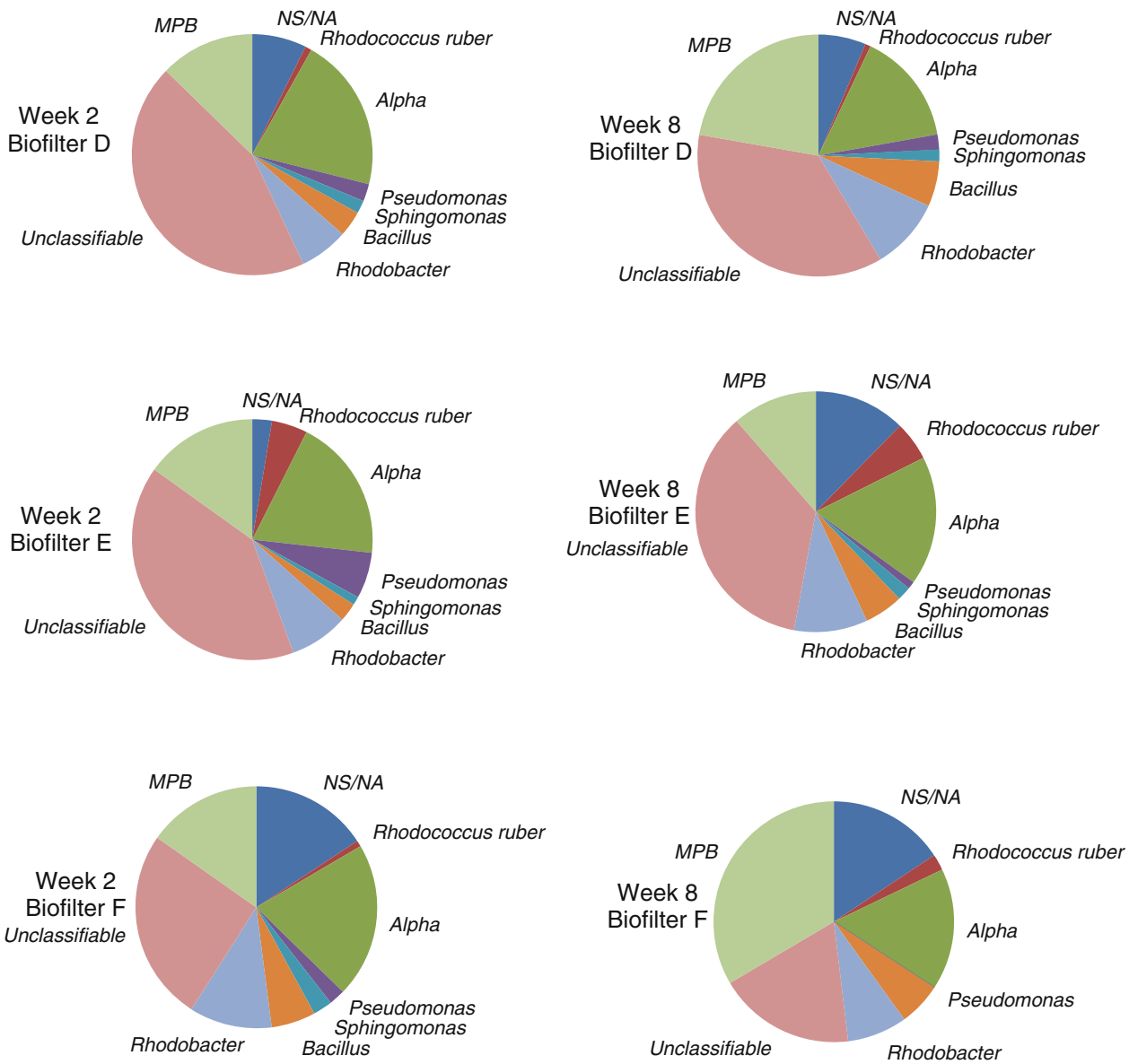
Fig. 6 a Phylogenetic neighbor-joining tree of the $16 \mathrm{~S}$ rDNA sequences of cultivable bacteria isolated from biofilm biofilter samples. Isolate strains are named after their corresponding biofilter. Filled circle-positive alkB amplification. b Phylogenetic tree of V3 rDNA TGGE band isolates belonging to biofilm biofilter RNA extracted samples. Band isolates 401-415 belong to biofilter $E$. Band isolates 416-421 belong to biofilter $\mathrm{F}$ a

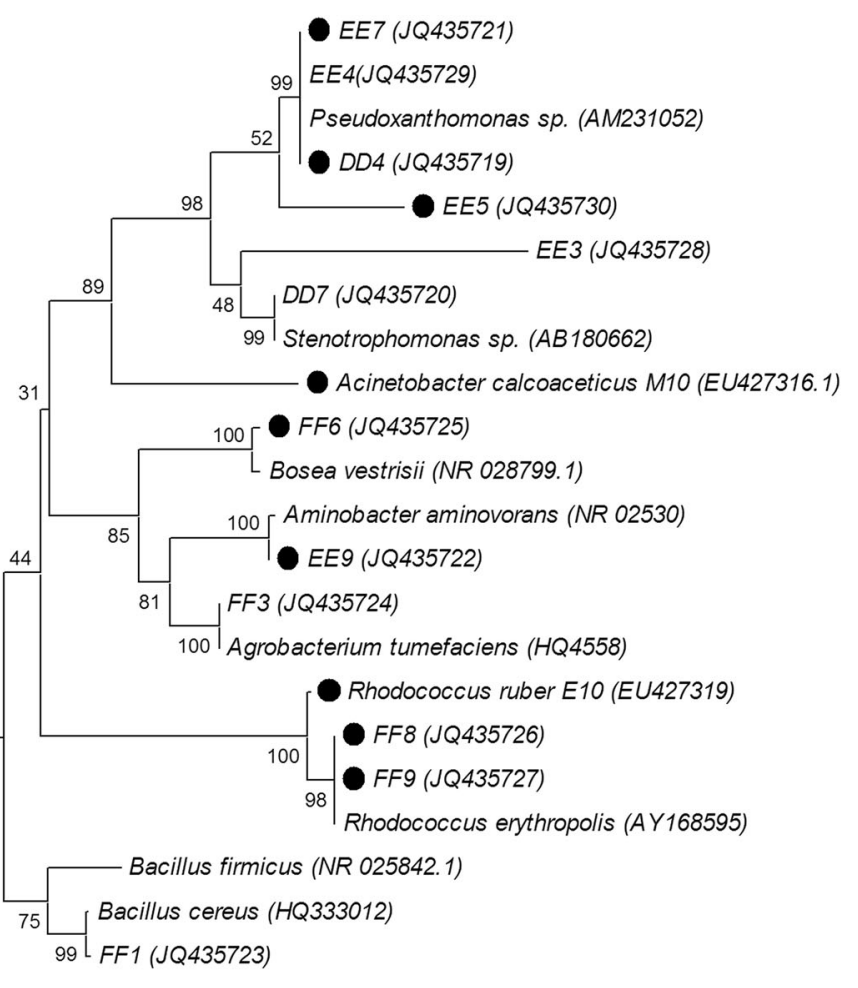

FF4 (JQ435731)

b

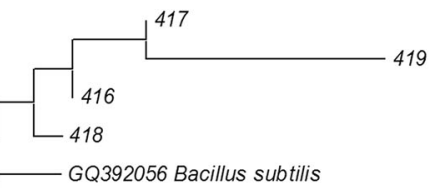

FJ372972 Uncultured Bacillus sp.

420

421

GQ226038 Bacillus cereus

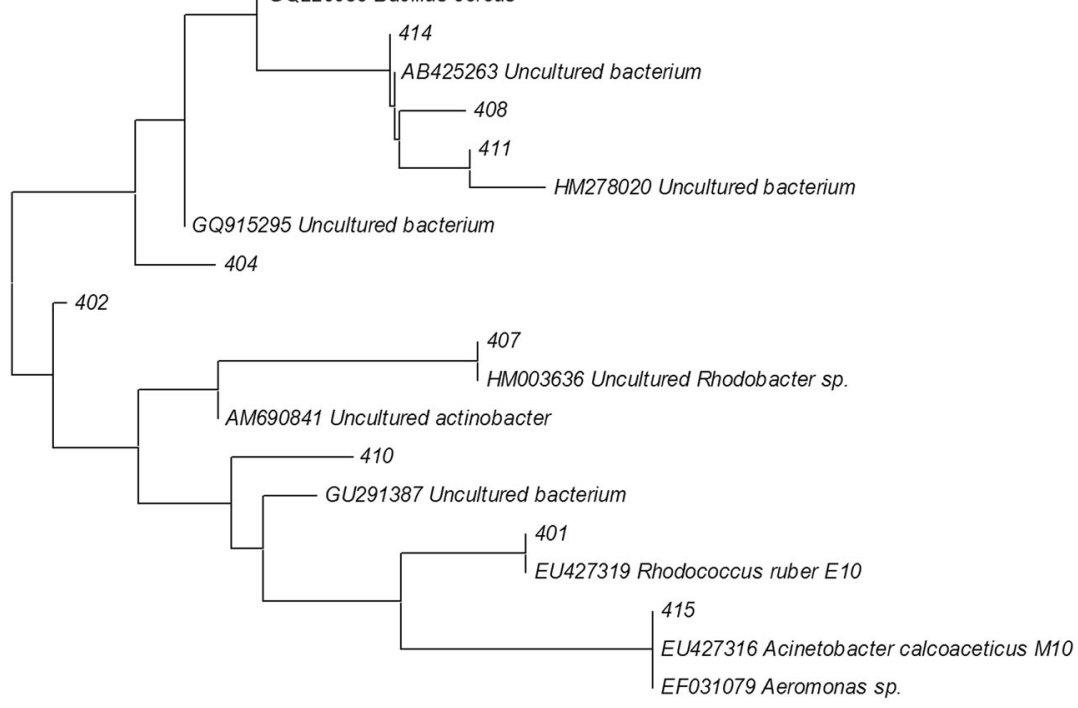

0.05 
Rhodobacteriaceae, as well as the non-presence of Pseudomonaceae and Sphingomonaceae. The amount of bands sequenced which were determined as "Unclassifiable" together with MPB (Mixed Population in a single Band) were always $>50 \%$ of the total band intensity. Thus, if the biodiversity observed at week 2 is different to that of week 8 (as observed in Fig. 3a), we can only assume that changes have occurred mainly within the population established as "Unclassifiable" and MPB.

The genre Bacillus, Sphingomonas, and Pseudomonas identified from the TGGE band isolates (Online Resource 1 Fig. 2b) are common to those found in another study from monitored contaminant sites using DGGE analysis (Kao et al. 2010). Bacillus strains were also cultivated from oxygenate-contaminated sources in this study (Fig. 6a), as well as Kao et al. (2010) and Barbera et al. (2011); however, this may be due to spore resistance and longevity in groundwater.

It is worth mentioning that no cultivable strain or TGGE band was identified as A. calcoaceticus in either week 2 or 8 in DNA extracts (Online Resource 1 Fig. 2b), nor among the cultivable strains (Fig. 6a); however, RNA TGGE band 415 from biofilter E was identified as A. calcoaceticus M10. Strain M10 did not survive in biofilter $D$ and this could have been caused by a dilution rate higher than the doubling growth of microorganisms, thus not allowing for growth nor maintenance. On the other hand, both strains E10 and M10 survived throughout the 8-week period in the biofilm and were active (even though the relative percentage of strain M10 within the biofilm was not high). Thus, specific strain inoculation in a biofilter will not ensure survivability of that strain. High populations of $R$. ruber were found in all biofilter communities with TGGE analysis of DNA extracts, but were highest in biofilter E (Fig. 5). In TGGE analysis of RNA extracts, the presence of strain E10 is observed in biofilter E (Fig. 6b). Thus, the initial seeded M10-E10 culture was still present and active after 8 weeks, but the concentration of E10 is probably higher than M10 since strain M10 was not detected among the DNA TGGE band isolates. In addition, alkB amplification of the bacterial strains R. ruber E10 and A. calcoaceticus M10 was positive for both; therefore, we infer that the co-culture M10-E10 is the main reason for MTBE removal in biofilter $\mathrm{E}$.

Strangely, retrieval of strains M10 or E10 among the cultivable bacterial isolates was not obtained. A biofilter study (de la Rúa et al. 2007) treating nitrate-rich groundwater observed that the selective denitrifying inoculum was not working and was substituted with other groundwater autochthonous strains which were decreasing nitrate concentrations. Although this not exactly what is happening with our seeded consortia, as stated above, we have observed that the microbial changes in the influent might alter the stabilization of the inoculum in the biofilm.
A phylogenetic tree of the isolated cultivable bacteria from the three biofilms at week 8 can be observed in Fig. 6a. All three biofilters contained at least one strain with positive $a l k B$ amplification. When comparing these isolates and those active as observed in Fig. $6 \mathrm{~b}$, there are only two matches: strains M10 and E10 from Biofilter E. As a consequence, amplification of the alkB gene of biological samples in biotechnologies does not imply MTBE degradation.

A denser biofilm and probably continuous consortium inoculation may help stabilize the biofilm. Reactors that use biofilms can maintain high biomass concentrations and are meant to be more resistant to external environmental changes (Bryers and Characklis 1989; Wilson et al. 1999); however, high biomass concentrations were not observed at the end of the experimental period. Co-metabolism such as alcohol injections observed in the work of Maciel et al. (2008), or of alkanes, could help the microbial community grow better, leading to a higher MTBE removal rate. The use of an MTBE adsorption material described by Baus and Brauch (2007) for a packed biofilter such as the one described in this study may also favor microbial attachment and growth, as well as removing high levels of MTBE from the liquid flow. Entrapment of bacterial cells such as the "water-in-oil-in-water" double emulsion described in Pimentel-González et al. (2008) could also be used with non-biofilm-forming strains such as E10 in biological reactors.

\section{Conclusion}

Inocula used in biotechnology may or may not be adapted to the engineered environment; thus, efficacy of singleculture laboratory strains may not proliferate as abundantly within a community. The co-culture formed by strains E10 and M10 withstood the biological and engineering stresses exerted throughout the experimental period, and these are mainly responsible for microbial MTBE removal with the help of autochthonous microbiota. Monitoring MTBE degradation through the sole use of molecular techniques such as alkB or ethB presence (either PCR or relative quantitative PCR) will not imply an active degrading community; thus, these tools should be used jointly with other methods to assess MTBE degradation.

Acknowledgments We would like to acknowledge the technical work performed by Juan de Dios Bueno Perez, Alicia Gonzalez Segura, and David Porcel Muñoz from the preparation of biological samples, scanning electron microscopy, and confocal laser microscope departments in the Centro de Instrumentación Científica from the University of Granada, Spain. This work was funded by the Spanish Ministerio de Ciencia y Tecnología, via the Programa Nacional de I $+D$ (project reference: CTM2006-02297). 


\section{References}

Aivalioti M, Vamvasakis I, Gidarakos E (2010) BTEX and MTBE adsorption onto raw and thermally modified diatomite. J Hazard Mater 178:136-143

Auffret M, Labbé D, Thouand G, Greer CW, Fayolle-Guichard F (2009) Degradation of a mixture of hydrocarbons, gasoline and diesel oil additives by Rhodococcus aetherivorans and Rhodococcus wratislaviensis. Appl Environ Microbiol 75:7774-7782

Barbera MJ, Mateo E, Monkaityte R, Constantí M (2011) Biodegradation of methyl tert-butyl ether by newly identified soil microorganisms in a simple mineral solution. World J Microbiol Biotechnol 27:813-821

Bass DH, Hastings NA, Brown RA (2000) Performance of air sparging systems: a review of case studies. J Hazard Mater 72: 101-119

Baus C, Brauch HJ (2007) Removal of MTBE and other fuel oxygenates during drinking water treatment. In: Barceló D (ed) Fuel oxygenates, 1st edn. Springer, Berlin, pp 275-330

Bryers JD, Characklis WG (1989) Biofilms in water and wastewater treatment. In: Characklis WG, Marshall KC (eds) Biofilm. Wiley Inc., New Jersey, p 671

Calderón K, Rodelas B, Cabirol N, González-López J, Noyola A (2011) Analysis of microbial communities developed on the fouling layers of a membrane-coupled anaerobic bioreactor applied to wastewater treatment. Biores Technol 7:4618-4627

Chauvaux S, Chevalier F, Le Dantec C, Fayolle F, Miras I, Kunst F, Beguin P (2001) Cloning of a genetically unstable cytochrome P-450 gene cluster involved in degradation of the pollutant ethyl tert-butyl ether by Rhodococcus ruber. J Bacteriol 183: 6551-6557

Chen H, Boutros PC (2011) VennDiagram: a package for the generation of highly customizable Venn and Euler diagrams in R. BMC Bioinform 12:35

de la Rúa A, Rodelas B, González-López J, Gómez MA (2007) Influence of temperature on microbial colonisation of clayey schist as a support media of a submerged filter for groundwater denitrification. Water Sci Technol 55:165-172

de Lacy Costello BP, Sivanand PS, Ratcliffe NM, Reynolds DM (2005) The rapid detection of methyl tert-butyl ether (MTBE) in water using a prototype gas sensor system. Water Sci Technol 52:117-123

Harcombe W (2010) Novel cooperation experimentally evolved between species. Evolution 64:2166-2172

Kao CM, Chen CS, Tsa FY, Yang KH, Chien CC, Liang SH, Yang CA, Chen SC (2010) Application of real-time PCR, DGGE fingerprinting, and culture-based method to evaluate the effectiveness of intrinsic bioremediation on the control of petroleumhydrocarbon plume. J Hazard Mater 15:409-416

Kerr B, Riley MA, Feldman MW, Bohannan BJ (2002) Local dispersal promotes biodiversity in a real-life game of rockpaper-scissors. Nature 418:171-174

Maciel H, Mathis H, Lopes Ferreira N, Lyew D, Guiot S, Monot F, Greer CW, Fayolle-Guichard F (2008) Use of Mycobacterium austroafricanum IFP 2012 in a MTBE-degrading bioreactor. J Mol Microbiol Biotechnol 15:190-198

Martín-Platero AM, Valdivia E, Maqueda M, Martínez-Bueno M (2007) Fast, convenient, and economical method for isolating genomic DNA from lactic acid bacteria using a modification of the protein "salting-out" procedure. Anal Biochem 366:102-104

Marzorati M, Wittebolle L, Boon N, Daffonchio D, Verstraete W (2008) How to get more out of molecular fingerprints: practical tools for microbial ecology. Environ Microbiol 10:1571-1581

Moraine RA, Rogovin P (1966) Kinetics of polysaccharide B-1459 fermentation. Biotechnol Bioeng 8:511-524

Onorati F, Mecozzi M (2004) Effects of two diluents in the Microtox toxicity bioassay with marine sediments. Chemosphere 54: 679-687

Pimentel-González D, Revah S, Campos-Montiel R, Monroy-Hermosillo O, Vernon-Carter EJ (2008) A laboratory study of the biodegradation of MTBE solubilised in water by a microbial consortium entrapped in a water-in-oil-in-water double emulsion. Process Biochem 43:1239-1243

Purswani J, Pozo C, Rodriguez-Diaz M, Gonzalez-Lopez J (2008) Selection and identification of bacterial strains with methyl $t$ butyl ether, ethyl $t$-butyl ether, and $t$-amyl methyl ether degrading capacities. Environ Toxicol Chem 27:2296-2303

Purswani J, Juárez B, Rodelas B, Gónzalez-López J, Pozo C (2011a) Biofilm formation and microbial activity in a biofilter system in the presence of MTBE, ETBE and TAME. Chemosphere 85: 616-624

Purswani J, Martin-Platero AM, Reboleiro-Rivas P, González-López J, Pozo C (2011b) Comparative analysis of microbial DNA extraction protocols for groundwater samples. Anal Biochem 416:240-242

Rosell M, Lacorte S, Barceló D (2007) Occurrence and fate of MTBE in the aquatic environment over the last decade. In: Barceló D (ed) Fuel oxygenates. Springer, Berlin, pp 31-55

Schmidt TC, Schirmer M, Weiâ H, Haderlein SB (2004) Microbial degradation of methyl tert-butyl ether and tert-butyl alcohol in the subsurface. J Contam Hydrol 70:173-203

Smith CA, O'Reilly KT, Hyman MR (2003) Characterization of the initial reactions during the cometabolic oxidation of methyl tertbutylether by propane-grown Mycobacterium vaccae JOB5. Appl Environ Microbiol 69:796-804

UNEP-United Nations Environmental Programme (2004) http:// www.grid.unep.ch/product/publication/freshwater_europe/ecosys. php Last accessed 06/09/2010

Waul CK, Arvin E, Schmidt JE (2007) Microbial degradation of MTBE in reactors. In: Barceló D (ed) Fuel oxygenates. Springer, Berlin, pp 213-238

Wilson BH, Shen H, Cho J, Vardy J (1999) Use of BIOSCREEN to evaluate natural attenuation of MTBE In: Alleman BC, Leeson A (ed) Natural attenuation of chlorinated solvents, petroleum hydrocarbons and other organic compounds. In: Proceedings 5th international in situ and on-site bioremediation symposium, San Diego, pp 115-120 